\title{
Correction to: Use of sterols and linear alkylbenzenes as molecular markers of sewage pollution in Southeast Asia
}

\author{
Margaret William Thomes $^{1,2} \cdot$ Vahab Vaezzadeh $^{1} \cdot$ Mohamad Pauzi Zakaria $^{1} \cdot$ Chui Wei Bong ${ }^{1,3}$ \\ Published online: 13 September 2019 \\ (C) Springer-Verlag GmbH Germany, part of Springer Nature 2019
}

Correction to: Environmental Science and Pollution Research https://doi.org/10.1007/s11356-019-05936-y

The original publication of this paper contains a mistake.

The correct image of figure 2 is shown in this paper.

The online version of the original article can be found at https://doi.org/ 10.1007/s11356-019-05936-y

Chui Wei Bong

cwbong@um.edu.my

Margaret William Thomes

margaretwilliam@hotmail.com

Vahab Vaezzadeh

vahab.vaezzadeh@um.edu.my

Mohamad Pauzi Zakaria

drpauzi@gmail.com

1 Institute of Ocean and Earth Sciences, University of Malaya, 50603 Kuala Lumpur, Malaysia

2 Institute for Advanced Studies, University of Malaya, 50603 Kuala Lumpur, Malaysia

3 Institute of Biological Sciences, Faculty of Science, University of Malaya, 50603 Kuala Lumpur, Malaysia 
Fig. 2 Maximum concentration of coprostanol in sediment (ng $\left.\mathrm{g}^{-1}\right)$ and water $\left(\mathrm{ng} \mathrm{L}^{-1}\right)$ in

Southeast Asia

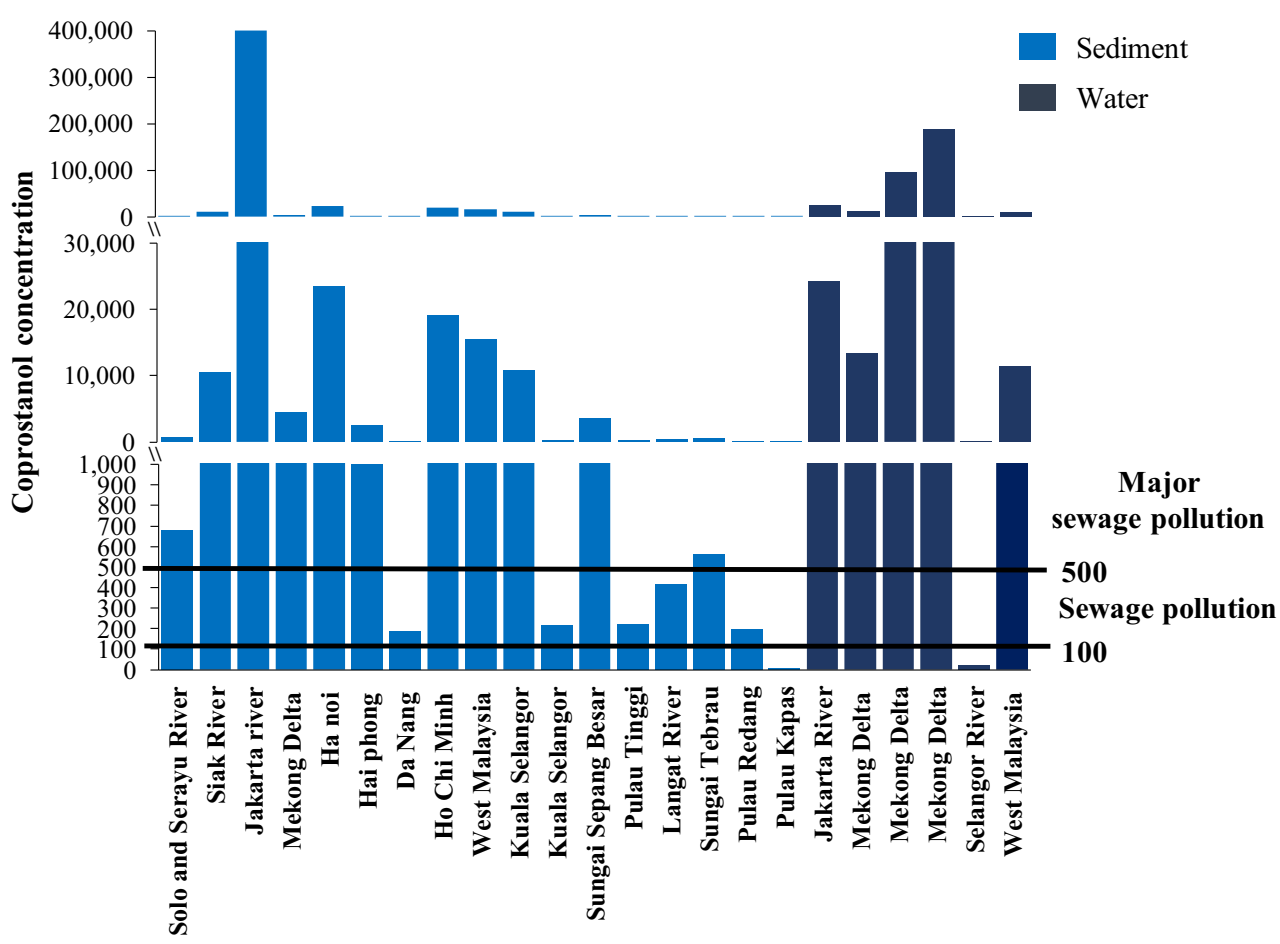

The original article was corrected.

Publisher's note Springer Nature remains neutral with regard to jurisdictional claims in published maps and institutional affiliations. 